\title{
Discriminación a consumidores con discapacidad visual acompañados por perros guía
}

\section{Edwin Gabriel Aldana Ramos}

Instituto Nacional de Defensa de la Competencia y de la Protección de la Propiedad Intelectual, Lima, Perú

Recibido: 5/6/2018 / Aprobado: 29/1/2019

doi: 10.26439/iusetpraxis2018.n48-49.4500

Resumen. El presente artículo relata una serie de casos protagonizados por personas invidentes en establecimientos públicos. Estos últimos habrían sido demandados por discriminación por prohibir a los discapacitados el ingreso con perros guía. A lo largo del artículo, se expone la jurisprudencia y las normas referentes a la discriminación, así como casos similares que permiten abordar temas como la libertad, la independencia y la autonomía de las personas discapacitadas cuando son acompañadas por estos canes.

PalabRas CLAVE: discapacidad / perros guía / discriminación / establecimientos públicos / autonomía / independencia / libertad / normas

\section{Discrimination against consumers with visually imparied patients accompanied by guide dogs}

АвsтRAct. This article tells us a series of events experienced by blind people in public establishments which were sued for discrimination because they prohibited said people from entering with guide dogs. Throughout the article, jurisprudence and regulations regarding discrimination, as well as similar events that enabled addressing issues such as the freedom, independence and autonomy disabled people have when accompanied by these dogs, were discussed.

KEYWORDS: disability / guide dogs / discrimination / public establishments / autonomy / independence / freedom / regulations 
Para esta limeña invidente, el significado que tiene su perro se resume en dos palabras: sus ojos. [...] Ella es muy importante para mí, es mi independencia. Tener un perro guía es maravilloso. La seguridad que te da la presencia de un perro así a tu lado es todo, no te sientes sola. Para tantas discapacidades y problemas emocionales ellos son una bendición. Lamentablemente en nuestra sociedad esto es algo que aún no se tiene muy en cuenta. [Testimonio de Jane Cósar]. (Carrión, 2017)

Para la mayoría de nosotros, es sencillo realizar actividades tan cotidianas como levantarse cada mañana a asearse, prepararse el desayuno, salir a hacer algún deporte, vestirse para ir a trabajar o estudiar, trasladarse a cualquier lugar, sea en transporte público o en movilidad particular. Nosotros, que tenemos el privilegio de quizás abrir las cortinas cada mañana y ver la luz del día, o por la noche encender la luz para desarrollar estas y otras actividades diarias, no nos percatamos de la importancia de la facilidad de poder hacer estas cosas cotidianas. Simples para nosotros, pero no tanto para otras personas. Esto de ningún modo significa que no puedan desarrollarlas de manera independiente, libre y autónoma, como es el caso de las personas invidentes ${ }^{1}$.

\section{Tres casos}

Imaginemos el primer caso expuesto ante la Comisión de Protección al Consumidor:

Una persona invidente acudió a un restaurante con su perro guía y se ubicaron en una de las mesas del local, casi en la entrada, pero resulta que el personal del establecimiento le solicitó que se retire, pues el can estaba incomodando al resto de comensales, además de que las normas sanitarias impiden el ingreso de animales al establecimiento y las normas de defensa civil prohíben la obstaculización del ingreso o salida de este tipo de locales. A pesar de que la comensal informó que es una persona invidente y que necesitaba de su perro, que es guía, que estaba debidamente entrenado y que era necesario para su asistencia y desplazamiento, el personal del restaurante le indicó que no la iba a atender y que tenía que retirarse, amenazándola incluso con arrojarle agua hirviendo. (Resolución 331-2013/CC2, 2013)

1 Los comentarios vertidos por el autor en el presente artículo son efectuados a título personal y no involucran en modo alguno a los órganos funcionales de Indecopi o a la entidad misma. 
Conforme a lo anterior, en el siguiente caso del Tribunal Constitucional:

Un grupo de personas con discapacidad visual acudieron a un supermercado, que días antes había publicado un comunicado en el que informaban que se restringiría el ingreso de todo tipo de animales a sus establecimientos comerciales, por razones de sanidad. Pese a que necesitaban estar acompañadas por sus perros guía, el establecimiento les prohibió en reiteradas oportunidades el ingreso al local. El supermercado señaló que con base en el Reglamento Sanitario de Funcionamiento de Autoservicios de Alimentos y Bebidas informó al público en general que iba a restringir el ingreso de todo tipo de animales a sus locales, por razones de sanidad, y que su personal estaba a disposición de las personas con discapacidad que requieran asistencia, por lo que había implementado un sistema que permitía el cuidado de los perros guía mientras el cliente hiciera sus compras. (Expediente 02437-2013-PA/TC, 2014)

Por último, en el tercer caso de la Comisión de Protección al Consumidor:

Una persona invidente acudió a un restaurante con su perro guía, pero esta vez estaba acompañada, además, por unos familiares. Personal del local le indicó que su perro debía permanecer fuera del local, que, al estar en compañía de personas mayores, la podían asistir mientras estuviera ahí y que su perro podía ser cuidado por personal de seguridad del establecimiento. Adicionalmente, el proveedor señaló que, de acuerdo con una ordenanza municipal, estaba prohibido el ingreso de canes a restaurantes por razones de salud pública y que la consumidora no mostró que su perro guía estuviera registrado en el Consejo Nacional para la Integración de la Persona con Discapacidad (Conadis). Finalmente, el proveedor señaló que la Ley 29830, Ley que promueve y regula el uso de perros guía por personas con discapacidad visual, no se pone en el supuesto de que la persona con discapacidad se encuentre acompañada de otras personas que puedan asistirla, lo cual constituiría un vacío legal. (Resolución978-2017/CC2, 2017)

¿Qué tienen en común estos casos, que son reales? Los afectados son personas con discapacidad visual que son asistidas por perros guía. En los tres, aparece por lo menos una vez la misma persona afectada con su perro guía, lo cual, además, evidencia una realidad: existen pocos perros guía en el Perú.

En el artículo del diario Perú21 titulado “¿Por qué hay tan pocos perros guía en el Perú?" (2016), se menciona que "a mayo del 2016 solo 
existirían cuatro perros guía acreditados y registrados en nuestro país" (párr. 14). En concordancia con lo anterior, el informe nacional del Instituto Nacional de Estadística e Informática (2018), manifiesta que "es una cifra ínfima considerando que en el Perú 3 millones 51 mil 612 personas padecen de alguna discapacidad; de esa cifra 1 millón 473 mil 583 tienen dificultad para ver" (p. 179).

Los hechos referidos en los tres casos anteriores se produjeron en establecimientos abiertos al público que ofrecían productos o servicios para el consumo (dos restaurantes y un supermercado), lo que está comprendido en la definición de proveedor contemplada por el Código de Protección y Defensa del Consumidor ${ }^{2}$. Los proveedores, por su parte, alegaron, como argumentos para la limitación del acceso o permanencia de la persona con discapacidad visual asistida con su perro guía, medidas sanitarias e incomodidad del resto de consumidores. Asimismo, en dos de los casos, los proveedores plantearon "alternativas" o "soluciones" para que el consumidor con discapacidad visual pueda hacer uso de sus servicios (sea de restaurante o de venta de productos), mientras el perro guía era cuidado por personal del proveedor en las afueras del establecimiento.

En efecto, el supermercado señaló que tenía implementado un sistema por el que asignaban personal de asistencia a las personas con discapacidad visual mientras realizaran sus compras. En uno de los restaurantes, ya que la consumidora con discapacidad venía acompañada también con otras personas mayores (su familia), le indicaron que ellas podían asistirla en el interior del establecimiento.

En los tres casos, se denunciaron actos de discriminación, con una demanda de amparo llevada en primera instancia ante el Sexto Juzgado

2 Ley 29571, Código de Protección y Defensa del Consumidor Artículo IV.- Definiciones

Para los efectos del presente Código, se entiende por: [...]

2. Proveedores.- Las personas naturales o jurídicas, de derecho público o privado, que de manera habitual fabrican, elaboran, manipulan, acondicionan, mezclan, envasan, almacenan, preparan, expenden, suministran productos o prestan servicios de cualquier naturaleza a los consumidores. En forma enunciativa y no limitativa se considera proveedores a:

1. Distribuidores o comerciantes.- Las personas naturales o jurídicas que venden o proveen de otra forma, al por mayor o al por menor, productos o servicios destinados finalmente a los consumidores, aun cuando ello no se desarrolle en establecimientos abiertos al público. 
Especializado en lo Constitucional de la Corte Superior de Justicia de Lima y dos denuncias ante la Comisión de Protección al Consumidor de Indecopi. La demanda llegó hasta el Tribunal Constitucional, mientras que, en la vía administrativa, las decisiones emitidas por la primera instancia quedaron consentidas. El Tribunal Constitucional, finalmente, declaró fundada la demanda de amparo. En cambio, el órgano resolutivo de Indecopi declaró infundadas ambas denuncias en el extremo referido a los actos de discriminación, y fundadas, en un caso, la infracción al deber de idoneidad ${ }^{3}$ y, en el otro, la infracción a la obligación de garantizar la atención preferente a las personas con discapacidad ${ }^{4}$.

\section{¿IDONEIDAD O ATENCIÓN PREFERENTE?}

Antes de entrar al análisis sobre el enfoque de discriminación en estos casos, cabe preguntarnos en las denuncias resueltas por Indecopi si estamos ante una infracción al deber de idoneidad o ante la obligación de garantizar la atención preferente a las personas con discapacidad.

De acuerdo con la Comisión de Protección al Consumidor 2, el caso se enfocó desde la perspectiva del deber de idoneidad. A saber, el hecho fue que "el proveedor denunciado les habría negado (a los denunciantes) el acceso al establecimiento, así como la prestación del servicio de alimentación a los denunciantes por ser personas con discapacidad y estar con la compañía de sus perros guía" (Resolución 331-2013/CC2, 2013). El sustento para abordar el caso como una infracción al deber de idoneidad fue que los proveedores ofrecen una garantía respecto de la idoneidad de los servicios que ofrecen, en función de la información transmitida expresa o tácitamente.

El razonamiento del órgano resolutivo se fundamentó en el hecho de que existían dos normas por considerar: la Ordenanza Municipal 984 de la Municipalidad Metropolitana de Lima -Nuevo Régimen

3 Ley 29571, Código de Protección y Defensa del Consumidor.

4 Artículo 41.- Trato preferente de gestantes, niñas, niños, adultos mayores y personas con discapacidad

41.1 El proveedor está en la obligación de garantizar la atención preferente de gestantes, niñas, niños, adultos mayores y personas con discapacidad, en todos los sistemas de atención con que cuente, debiendo facilitar al consumidor todos los mecanismos necesarios para denunciar el incumplimiento de esta norma bajo responsabilidad. 
Municipal de Aplicación de Sanciones Administrativas Derivadas de la Función Fiscalizadora ${ }^{5}$ - y la Ley 29830, Ley que promueve y regula el uso de perros guía por personas con discapacidad visual. Si bien - como se indica en la resolución - al momento de ocurridos los hechos la ley no se encontraba reglamentada, ambas normas otorgaban el derecho de las personas con discapacidad visual a acceder a establecimientos comerciales, como el restaurante, en compañía de sus perros guía. La ordenanza municipal, por su parte, restringía el acceso a establecimientos comerciales de animales y canes considerados peligrosos, con excepción de perros guía, como era el caso de los denunciantes.

Al no respetarse esto, la Comisión consideró que se infringieron ambas disposiciones y, en consecuencia, se afectó el derecho de los consumidores con discapacidad visual a ingresar a este tipo de lugares debidamente asistidos por sus perros guía. Lo que se entiende de la resolución es que un consumidor esperaría que, al existir disposiciones legales como las descritas, el proveedor garantice su cabal cumplimiento para que el servicio se brinde conforme a sus expectativas. No cumplir normas sectoriales, como las citadas, constituye una infracción al deber de idoneidad.

Pero imaginemos que no se hubieran dado ni la ordenanza ni la ley, ¿el caso podría ser declarado infundado desde la óptica del deber de idoneidad? Considero que no, ya que el Código de Protección y Defensa del Consumidor indica que también hay una garantía implícita $^{6}$, que permitiría tomar en cuenta que una persona con este tipo de

5 Anexo I: Establece la tipificación y la escala de multas aplicables dentro de la jurisdicción de la Municipalidad Metropolitana de Lima

Línea de acción 02: Salud y salubridad [...]

Ingresar con canes considerados peligrosos a locales de espectáculos públicos, deportivos, culturales o cualquier otro en donde haya asistencia masiva de personas, con excepción de los canes guía de personas con discapacidad y aquellos que estén al servicio de la Policía Nacional, Fuerzas Armadas o el Serenazgo. [Las cursivas son mías].

6 Artículo 20.- Garantías

Para determinar la idoneidad de un producto o servicio, debe compararse el mismo con las garantías que el proveedor está brindando y a las que está obligado. Las garantías son las características, condiciones o términos con los que cuenta el producto o servicio. $[\ldots]$

c. Una garantía es implícita cuando, ante el silencio del proveedor o del contrato, se entiende que el producto o servicio cumplen con los fines y usos previsibles para los que han sido adquiridos por el consumidor considerando, entre otros aspectos, los usos y costumbres del mercado. 
limitaciones (discapacidad visual) necesita la asistencia de lo que él considere indispensable para el uso adecuado del servicio, en este caso, el perro guía, siempre que no genere algún riesgo al resto de consumidores, como podría suceder con un perro que no sea guía, sino una mascota y que, además, sea peligroso (en principio, en este supuesto, se podría restringir, de manera justificada, el ingreso de algún consumidor con su mascota).

El enfoque fue desde la obligación del proveedor de garantizar la atención preferente de las personas con discapacidad, en tanto que en la Resolución 978-2017/CC2 (2017) se concluye que "no habría implementado las medidas para garantizar su ingreso (de la consumidora) acompañada de su perro guía - lazarillo-, mientras se encontraba en el establecimiento, pese a ser una persona con discapacidad visual". En este caso, se deduce que el órgano resolutivo descartó la imputación por presuntas infracciones al deber de idoneidad, porque los hechos estaban estrictamente referidos a que el personal del establecimiento no brindó un trato preferente a la denunciante al restringir y condicionar la atención hasta que el perro guía no fuera retirado del restaurante, aunque más parece la imposición de una condición para brindar el servicio.

El Código de Protección y Defensa del Consumidor (2010) reconoce lo siguiente:

La existencia de un grupo de personas en condición de vulnerabilidad, que requiere una mayor tutela por parte del Estado, mediante normas, políticas y programas que garanticen la reducción del estado de vulnerabilidad y permitan a dichas personas ejercer adecuadamente sus derechos. (p. 139)

A partir de ello, el artículo 41.1 de dicho dispositivo establece:

El proveedor está en la obligación de garantizar la atención preferente de personas con discapacidad en todos los sistemas de atención con que cuente, debiendo facilitar al consumidor todos los mecanismos necesarios para denunciar el incumplimiento de esta norma bajo responsabilidad.

De primera mano, pareciera que esta norma no cuadra con el hecho que se analiza, pues haría referencia más a una atención ventajosa de una persona frente a otra, en este caso, de una persona con discapacidad visual frente a otra que no tiene dicha discapacidad. Veamos. 
Si una persona con discapacidad visual se presenta en un establecimiento comercial, como un restaurante, la norma podría interpretarse en el sentido de que el proveedor deberá, por ejemplo, permitirle primero el acceso al local y su ubicación en alguna mesa antes que a otra persona que no tenga dicha limitación, si imaginamos que para acceder al local se ha formado una fila de espera. Lo mismo podría suceder para la toma de su orden, preparar y servirle el plato que solicite, y efectuar el pago correspondiente.

¿La misma interpretación podría hacerse si una persona con discapacidad visual se presenta en el local con un perro guía y desea acceder? Podríamos entender que la atención preferente, como se ha señalado, constituye la atención ventajosa de una persona frente a otra, en este caso, de la persona invidente que está con su perro guía frente al resto de personas. En este caso, se debe acceder, dada su condición, a que ingrese al establecimiento con su perro guía, cosa que no sucedería con una persona que no tenga dicha limitación, así acuda con un animal de este tipo, ya que, para que se presente el supuesto, ambas condiciones deben concurrir: persona invidente con su perro que debe ser guía.

Me convence más abordar el análisis de los hechos desde el punto de vista del cumplimiento del deber de idoneidad, puesto que existen disposiciones legales especiales que regulan esta materia. Así tenemos la Ley 29973, Ley General de Personas con Discapacidad; la Ley 29830, Ley que promueve y regula el uso de perros guía por personas con discapacidad visual, modificada por la Ley 30433; las ordenanzas municipales que prevén casos como el descrito (el uso de perros guía) y, sobre todo, dispositivos supranacionales como la Convención sobre los Derechos de las Personas con Discapacidad.

No tener en cuenta estos dispositivos atenta contra las expectativas del consumidor, que es recibir un servicio que sea acorde con dicho marco normativo. Considero que la atención preferente, si bien puede ser interpretada de modo tal que comprenda hechos como el descrito, encuadra más en otro tipo de situaciones, pues entiendo que se refiere a la atención ventajosa que debe tener una persona vulnerable, a la cual se tiene que preferir, frente a otra que no tiene alguna limitación.

Dicho esto, ¿cómo se abordaron los presuntos actos de discriminación en sede administrativa? Veamos. 


\section{¿Discriminación?}

En la Resolución 331-2013/CC2 (2013), la Comisión consideró lo siguiente:

22. Sobre el particular, merituados los medios probatorios y de los hechos expuestos en los párrafos precedentes, se evidencia que:

Los denunciantes no fueron impedidos de ingresar al establecimiento comercial, en la medida que accedieron al mismo y se sentaron en la primera mesa, en compañía de sus canes.

Habiendo ingresado al restaurante, personal de la denunciada les solicitó en reiteradas ocasiones que se retiraran, en tanto los canes obstaculizaban el ingreso de los comensales, hecho que es posible verificar del video presentado por los denunciantes en calidad de medio probatorio.

Ha quedado evidenciado que la solicitud hecha a los denunciantes a efectos de que se retiran del establecimiento comercial no fue por su condición de invidentes, sino por haber ingresado en compañia de sus canes. [...]

24. En ese orden de ideas, este Colegiado considera que no se cuenta con indicios que permitan presumir que los denunciantes fueron discriminados, en la medida que lograron ingresar al establecimiento, y si bien luego les fue negada la atención solicitándoles que se retiraran, ello no constituye necesariamente un acto de discriminación, más aún considerando que ha quedado evidenciado que la razón por la cual se les pidió que se retiraran no fue por su condición de invidentes, sino por la permanencia de los canes dentro del restaurante. [Las cursivas son mías].

En la Resolución 978-2017/CC2 (2017), cuatro años después, la Comisión, con distinta conformación, declaró:

33. En esa línea de ideas y en atención a los alegatos y medios probatorios aportados por las partes, se evidencia que la señora Cósar no fue impedida de ingresar al establecimiento denunciado, en la medida que accedió al mismo junto a su perro guía y en compañía de su familia. No obstante, habiendo ingresado al restaurante, personal de... le solicitó que el can debía esperar fuera del local.

34. Así, ha quedado evidenciado que la solicitud hecha por el personal del proveedor denunciado a efectos de contar con la autorización para retirar al can del establecimiento comercial no fue por la condición de invidente de la señora Cósar, sino en tanto consideraban que, al estar acompañada de sus familiares, estos podían asistirla mientras permaneciera dentro del restaurante. 
35. Lo indicado en el párrafo anterior no es un argumento que este Colegiado considere que se encuentra correcto, sino que únicamente está evaluando si el accionar del personal de... constituye un acto de discriminación en contra de la señora Cósar.

36. En ese orden de ideas, este Colegiado considera que no se cuenta con indicios que permitan presumir siquiera a nivel indiciario que la denunciante fue víctima de trato discriminatorio por parte del personal de [...], en la medida que logró ingresar al establecimiento denunciado, y si bien luego se le pidió autorización para retirar al can que la acompañaba, no se restringió el ingreso tanto de ella como de su familia que la acompañaba. [Las cursivas son mías].

En ambos casos, el órgano colegiado consideró que no se produjo el acto de discriminación. Esta determinación se basó en que no se impidió el ingreso de la persona con discapacidad visual al local; asimismo, en el primer caso, el proveedor le indicó que debía retirarse, pues su can obstaculizaba el paso, mientras que, en el segundo, al estar acompañada de familiares que la podían asistir, el proveedor le solicitó autorización para que el can permanezca fuera del establecimiento. De esta manera, se concluyó que las solicitudes no fueron hechas por la condición de invidentes de las personas afectadas.

El Código de Protección y Defensa del Consumidor establece en el literal d) del artículo 1 que reconoce el derecho de los consumidores a ser tratados justa y equitativamente en toda transacción comercial y a no ser discriminados por motivo de origen, raza, sexo, idioma, religión, opinión, condición económica o de cualquier otra índole. Conforme a la jurisprudencia en esta materia, los proveedores tienen la obligación de dispensar un trato equitativo a los consumidores, brindando sus servicios o productos sin exclusiones o selección de clientela, más allá de las condiciones que objetivamente resulten necesarias para el cabal cumplimiento de sus prestaciones.

En esa línea, el artículo 38 del Código de Protección y Defensa del Consumidor (2010) instituye expresamente:

La prohibición de discriminar a los consumidores por motivo de origen, raza, sexo, idioma, religión, opinión, condición económica o de cualquier otra índole; encontrándose prohibida la exclusión de personas sin que medien causas de seguridad del establecimiento, tranquilidad de sus clientes u otros motivos similares. Asimismo, se precisa que el trato diferenciado debe obedecer a causas objetivas y razonables. (p. 17) 
Teniendo en cuenta este contexto normativo, considero que la discriminación no solo se da por el acceso o no a un establecimiento comercial, que es el caso más común desarrollado en el ámbito administrativo, como el acceso a discotecas o la contratación de seguros o productos bancarios, entre otros. Los actos de discriminación pueden darse aun estando ya en el interior de un establecimiento, y el trato discriminador podría ocurrir a partir de ese momento, esto es, aunque la relación de consumo ya se haya configurado, pero lo usual es que la relación de consumo no se genere justamente por la negativa del proveedor a brindarle un bien o servicio al consumidor discriminado.

Por ejemplo, imaginemos una discoteca en la que el proveedor discriminador establezca que se cobre un precio determinado para el ingreso, pero que a personas con determinadas características se les cobre cinco veces más ese monto para impedir o disuadir de alguna manera su decisión de ingreso. Supongamos que el consumidor al que se le cobra así pague y que, desde ese momento, aun habiendo ingresado, esté siendo víctima de hostigamiento al venderle más caros las bebidas y los alimentos, en comparación con otros consumidores, para que se retire. A pesar de haber ingresado al recinto, estaría siendo objeto de conductas discriminadoras. El problema es probatorio, pero que existe discriminación, existe, a mi entender.

De acuerdo con las resoluciones de Indecopi antes señaladas, en un caso, se solicita al consumidor retirarse con su perro, pues el can obstaculizaba el tránsito y, en el otro, se pidió que el perro se quedara en la entrada y que la consumidora sea asistida por sus familiares. En ambas situaciones, en la mente del proveedor, el problema era el perro guía, sea por razones de sanidad o por la seguridad e incomodidad de otros usuarios, pero el efecto iba más allá de este fin y resultó contraproducente.

\section{Algunos casos similares en la jurisprudencia comparada}

¿Usted cree que este tipo de situaciones se producen solo en nuestro país? Veamos tres casos de Costa Rica en los años 2004, 2005 y 2011.

\section{Caso 1}

A través de Sala Constitucional de la Corte Suprema de Justicia de Costa Rica, a las 10:15 horas del 17 de agosto del 2004, el recurrente interpone recurso de amparo contra MOREIRA ARAYA ASDRÚBAL, en su 
condición de propietario del restaurante LA PRINCESA MARINA, y manifiesta que desde su nacimiento padece de glaucoma congénito, motivo por el cual es ciego completamente y ocupa la ayuda de un perro lazarillo debidamente entrenado [las cursivas son mías]. Afirma que el quince de agosto pasado, a las quince horas veinte minutos, se presentó con su companera al restaurante La Princesa Marina ubicado en Curridabat para celebrar el Día de la Madre. Quien les atendió les indicó que debía consultar si podían entrar con el perro guía y posteriormente les dijo que uno de los dueños del restaurante, el aquí recurrido, le indicó que no podían entrar al restaurante con el perro guía [las cursivas son mías] y que no le importaba que la Ley de Igualdad de Oportunidades estableciera la obligación de permitirle la entrada al restaurante con el perro guía. Considera que se le ha discriminado por su condición de no vidente. Solicita el recurrente que se declare con lugar el recurso, con las consecuencias legales que ello implique. (2004)

\section{Caso 2}

Por escrito recibido en la Secretaría de la Sala a las catorce horas veinticinco minutos del diez de agosto del dos mil cuatro. El recurrente interpone recurso de amparo contra la Cooperativa de Transportes de Servicios Públicos y Servicios Múltiples Irazú R. L. y el señor Gerardo Mora Rodríguez, y manifiesta que desde su nacimiento padece una enfermedad llamada glaucoma congénito y por esa razón es totalmente ciego. Que debido a esto ocupa la indispensable ayuda de un perro lazarillo o guía. Que cuenta con un animal entrenado en el estado de Michigan en la escuela Leader Dog. Que a las 22:30 horas del día jueves 15 de julio del año en curso, mediante Resolución N. ${ }^{\circ}$ 205-07768 se solicitó una unidad de taxi a la cooperativa recurrida, debido a que se encontraba en el distrito de Hatillo en compañía de su esposa Zulia Oquendo Vejarano y la hija de esta última, Ariadna Cortez Oquendo, que al igual que el amparado es no vidente [las cursivas son mías].

Según, la operadora de turno en la cooperativa le informó que el carro que llegaría por ellos era el Z36 PLACA TSJ 700. Que, sin embargo, cuando el taxi se presentó y su conductor, de nombre Gerardo Alvarado Solano, se dio cuenta de que el recurrente necesitaba viajar con un perro lazarillo, simplemente arrancó y se fue [las cursivas son mías]. Que el recurrente abordó un taxi de otra cooperativa y, cuando llegó a su casa, se comunicó nuevamente con la operadora de Cooperativa Irazú para comentarle lo sucedido. Que ella le ofreció sus disculpas y procedió a comunicarse por radio con el chofer de la placa supra citada.

Sin embargo, cuando la operadora le habló de lo sucedido al conductor, indicándole claramente que el cliente iba a interponer un recurso de amparo, el individuo manifestó que a él no le importaba este hecho, que 
en lo que a él concernía no había ningún problema con que lo denunciaran, y que, aunque había visto claramente que el perro era de un ciego, no lo iba a llevar, pues no le importaba [las cursivas son mías]. Que el recurrente pudo escuchar la conversación del chofer y la operadora a través de la línea telefónica. (2005)

\section{Caso 3}

Por escrito recibido mediante el sistema de fax de la Sala a las 12:37 horas del 22 de junio del 2011, la recurrente interpone recurso de amparo contra el Colegio Humboldt, y manifiesta que es una persona no vidente, por lo que utiliza como ayuda técnica para su desplazamiento una perra guía, de nombre Allie, cuyo número es 10827, raza labradora, color negro, entrenada y graduada en la escuela Leader Dogs for the Blind, Michigan-Rochester, Estados Unidos. En la Resolución 2011-011418 indica que pertenece al Sistema Nacional de Educación Musical (SINEM) como instructora del programa para niños con discapacidad llamado MAT (Música con Accesibilidad para Todos), y el 20 de junio del 2011, en horas de la tarde tenían su primer recital del año, actividad programada en el colegio recurrido. No obstante, al momento de ingresar a la institución recurrida, unos oficiales de seguridad le imposibilitaron su acceso al mismo, bajo el argumento de no dejarla de pasar con su perra guía, pese a que les explicó que era una persona con discapacidad visual. Sin embargo, le indicaron que por disposición del propio Colegio Humboldt no era posible el ingreso a las instalaciones [las cursivas son mías]. Por las razones expuestas, estima lesionados sus derechos fundamentales. (2011)

Un restaurante, un servicio de taxi y un colegio. Tres tipos de servicios a los que personas con discapacidad visual intentaron ingresar y fueron impedidos por estar con sus perros guía, acompañados o no de otras personas, invidentes o no. El primer caso es muy parecido a los que fueron materia de resolución por parte de la Comisión de Protección al Consumidor.

En el caso del restaurante, el proveedor invocó también, ¡oh, casualidad!, normas de salud y señaló que informó al consumidor que podía ingresar al local, pero sin el perro, ya que por ser Día de la Madre el local estaba copado, tanto así que el consumidor tuvo que esperar para obtener mesa. Además, estaba acompañado de otra persona que no era invidente, quien sustituía en gran medida su necesidad de apoyo.

En el caso del servicio de taxi, el taxista negó lo manifestado por el afectado y señaló que, al dirigirse a recoger al pasajero, subió en 
realidad a otra persona que no tenía perro, creyendo que esta era la persona que había pedido el taxi. Ignoraba, según él, quién era el taxista que se presentó en el lugar y que se negó a brindar el servicio.

En el caso del colegio, si bien no se encuadraría en la protección al consumidor, pues la afectada no estaría comprendida en una relación de consumo, reconocieron que habían actuado de manera incorrecta e inoportuna. Le brindaron las disculpas del caso, pero precisaron que el personal de seguridad tuvo dudas sobre cómo proceder en cuanto al ingreso del perro guía al auditorio, ya que había un recital, y que si bien había restricciones para el acceso de animales domésticos, ello no aplicaba para los perros guía. En esa situación, alega el colegio, se encontraban ante un conflicto entre dos intereses: la protección de la salud de los alumnos y el derecho de acceso irrestricto de una persona invidente con su perro guía. Como ocurrió en los casos peruanos, se ofreció a la afectada cuidar de su perro guía en la entrada del establecimiento y el apoyo para su traslado al auditorio del colegio.

El análisis que hace la Sala Constitucional es interesante, pues parte del derecho de exclusión en propiedad privada que tiene todo legítimo poseedor de un inmueble de propiedad privada. En el Perú, el artículo 70 de la Constitución Política del Perú (1993) dispone que "el derecho de propiedad es inviolable. El Estado lo garantiza. Se ejerce en armonía con el bien común y dentro de los límites de ley [...]" (p. 16). Teniendo el derecho a la propiedad consagración constitucional, señala la Sala Constitucional, quien ejerce la titularidad, posesión o usufructo de un inmueble de propiedad privada puede determinar a quiénes autoriza o no el ingreso. Lo contrario ocurre cuando se trata de un inmueble de propiedad privada destinado en todo o en parte para uso del público, como, por ejemplo, al ofrecer espectáculos públicos a cambio de un precio e incluso de manera gratuita. En este sentido, la Resolución 2011-011418 expresa:

Limitándose con ello al poseedor legítimo del inmueble la posibilidad de restringir el acceso del público a la parte destinada precisamente para ese fin [las cursivas son mías], puesto que si aquel está facultado en ciertos casos para condicionar o restringir el ingreso de algunas personas, lo cierto es que nunca será constitucionalmente válida la exclusión si con ello se infringe o amenaza los derechos fundamentales de esas personas, sea causando discriminación, un trato indigno o denigrante, o coartándole con ello alguna libertad pública [las cursivas son mías] reconocida constitucionalmente o en convenios internacionales aprobados por nuestro país, puesto que con ello estaría ejerciendo abusivamente su derecho. (2011) 
Verificado el empleo de mi propiedad privada para brindar servicios al público, la restricción de acceso del público se levanta, y la exclusión de alguna persona podría configurar un acto de discriminación. A partir de esta premisa, la Sala Constitucional analiza el derecho de las personas con discapacidad visual. Es muy interesante que reconozca que se trata de una protección especial que otorga el ordenamiento jurídico a este grupo de personas y que no es simplemente un trato especial en atención a las particulares condiciones de esa población, sino un derecho de esta y una obligación para el resto de las personas respetar esos derechos y cumplir con las obligaciones que de ellos se derivan. Reafirmo, entonces, el hecho de que se puede revaluar la aplicación del artículo 41.1 del Código de Protección y Defensa del Consumidor sobre la obligación de garantizar el trato preferente a personas con discapacidad, en el caso resuelto en Indecopi, pues la afectación va más allá del cumplimiento de esta obligación y puede constituir un posible acto de discriminación.

Sobre la base del principio de igualdad de las personas y los derechos de las personas con discapacidad reconocidos en convenios internacionales, la Sala Constitucional entiende como discriminación toda distinción, exclusión o restricción fundada en una discapacidad, con el propósito de impedir o anular el reconocimiento, goce o ejercicio de las personas con discapacidad de sus derechos humanos y libertades fundamentales. En la otra cara de la moneda, se encuentra la obligación del Estado de adoptar medidas para eliminar progresivamente la discriminación y promover la integración en la prestación de bienes, servicios, instalaciones, programas y actividades como empleo, transporte, comunicaciones, vivienda, recreación, educación, deporte, etcétera.

Si se limita la posibilidad de que la persona con discapacidad visual tenga a su perro guía a su lado, se perjudica la posibilidad de que se integre en igualdad de oportunidades, más aún si se sabe que se trata de un perro debidamente entrenado y acreditado, bajo condiciones adecuadas de higiene. Limitar el acceso de las personas con discapacidad a lugares públicos contraviene la obligación de cumplir con las disposiciones constitucionales, legales e internacionales de garantizar el acceso de estas personas en igualdad de condiciones. Así, constituirá un acto de discriminación la negativa a la persona de participar en las actividades que desarrollan, en este caso, los proveedores, colocándolas, por el contrario, en un estado de desigualdad y discriminación frente a otras personas que pueden tener movilidad sin ayuda de nada ni de nadie. 
En los tres casos costarricenses, la Sala Constitucional consideró que se produjeron actos de discriminación.

\section{EL CASO DE DISCRIMINACIÓN EN EL SUPERMERCADO}

Regresemos al caso del supermercado en Lima. Se trata de una demanda de amparo que, finalmente, el Tribunal Constitucional conoció por el recurso de agravio constitucional contra la resolución emitida por la Quinta Sala Civil de la Corte Superior de Justicia de Lima, que declaró infundada la demanda. Esta resolución señaló que la medida de restricción de ingreso de los demandantes con sus perros guía al local estaba justificada por razones sanitarias.

Además, en el Expediente 02437-2013-PA emitido por el Tribunal Constitucional, la demandada indicó que se había implementado un protocolo de atención en tiendas de clientes con discapacidad, políticas de trato adecuado y en condiciones de igualdad, ofreciéndoles la asistencia de un colaborador y el cuidado de los perros guía mientras realicen sus compras, y agregó:

Las medidas adoptadas por la demandada son razonables, toda vez que para elegir el producto de consumo humano y apreciar su calidad, los precios y las marcas no se necesita la presencia de los perros guía, sino el concurso de una persona. (2014).

Con esta premisa, el Tribunal Constitucional señaló que, en el caso de las personas con discapacidad, existe la obligación constitucional del Estado de garantizarles el respeto a su dignidad y un régimen legal de protección, atención, readaptación y seguridad, comprendiendo "el deber estatal de establecer ajustes razonables orientados a promover las condiciones necesarias que permitan eliminar las exclusiones de las que históricamente han sido víctimas" (p. 5).

Es clave entender lo que señala el Tribunal Constitucional en el sentido de que no se trata de adoptar estas medidas por la discapacidad en sí misma, sino que la exclusión de las personas con discapacidad en los procesos de nuestra sociedad se origina por las condiciones y características del ambiente o entorno social en el que se han visto forzadas a interactuar. Si nos percatamos, continúa el Tribunal, todas las actividades en las que participamos han sido planificadas para desarrollarse en ambientes físicos que se ajustan a los requerimientos y necesidades de las personas que no tienen dicha discapacidad. Esto es, ha 
respondido a la imagen de un ser humano sin deficiencias físicas, sensoriales o mentales, lo que provoca marginación y posterior exclusión de este sector de la población con discapacidad, al impedir que acceda al goce y ejercicio pleno de sus derechos y libertades.

El derecho internacional de los derechos humanos provee de principios que fundamentan la implementación de las medidas que permiten a las personas con discapacidad gozar y ejercer sus derechos fundamentales y de cualquier otra clase. Asimismo, en el párrafo 15 del Expediente 02437-2013 emitido por el Tribunal Constitucional (2014), se contempla lo siguiente:

15. En conjunto, dichos principios exigen que cualquier medida que se tome en esta materia se oriente a remover los obstáculos que impiden que las personas con discapacidad gocen de sus derechos de manera plena y puedan ejercerlos, en especial, aquellos que imposibilitan el acceso a ciertos entornos físicos, sin afectarse en ningún caso su autonomía, libertad e independencia [las cursivas son mías]. Ha de tratarse, pues, de medidas que fomenten el desarrollo autónomo de las personas con discapacidad en espacios físicos adecuados. (p. 7)

La mayor independencia, libertad y autonomía posible. Eso es lo que se busca garantizar desde el accionar del Estado mediante normas, políticas y exigencias a la sociedad, y desde la actividad que desarrollan, en el caso que comentamos, los proveedores a través del respeto y cumplimiento de estas disposiciones.

Para ello, contamos con normas que exigen la adecuación de la infraestructura de los establecimientos a donde acude el público (por ejemplo, rampas de acceso, servicios higiénicos acondicionados); normas que contemplan el derecho de uso de perros guía para las personas con discapacidad visual; así como normas que abordan la promoción, protección y realización en igualdad de condiciones de los derechos de las personas con discapacidad, las cuales exigen a los proveedores el cumplimiento de ciertas obligaciones para dicho fin. Como describimos en los casos costarricenses, hay dos caras de la misma moneda: de un lado, la obligación del Estado, que se complementa necesariamente con la actividad de los públicos y privados - los proveedores, en esta ocasión- para darle contenido.

En el caso del supermercado, el Tribunal Constitucional consideró que prohibir el acceso de las personas con discapacidad visual con sus perros guía a sus instalaciones constituye una "discriminación por indiferenciación", por impedirles el goce y ejercicio del derecho reconocido por 
la Ley 29830, Ley que promueve y regula el uso de perros guía por personas con discapacidad visual, al no permitirles ni acceder ni permanecer en el local de manera ilimitada, constante y sin trabas. Por el contrario, en el Expediente 02437-2013-PA (2014), expresa que "tratando de manera igual lo que no lo es, el supermercado omitió brindar un tratamiento diferenciado que se justifica por las necesidades especiales de las personas con discapacidad visual" (p. 12). En suma, denegar el goce de este derecho - de tener la asistencia del perro guía - debe considerarse, de acuerdo con el Tribunal, como una intervención (afectación) al derecho a la igualdad.

No solo afecta este derecho, sino también el derecho al libre desarrollo y bienestar, como indica el expediente del Tribunal Constitucional (2014):

Dificulta que las personas con discapacidad visual gocen de sus derechos y los ejerzan de acuerdo con los ajustes razonables establecidos por la legislación con el propósito de que puedan desarrollarse autónomamente en los establecimientos abiertos al público. Impide que las personas con discapacidad visual gocen de una plena movilidad personal y que interactúen con la mayor independencia posible. (p. 13)

Independencia, libertad y autonomía, no dejemos de recordarlo, ya que, en este caso, el Tribunal consideró que las mascotas no tienen injerencia en cómo se desenvuelven sus dueños, mientras que los invidentes encaran su deficiencia visual con la ayuda de los perros guía. Así, en el párrafo 36 de dicha sentencia, se determina "que se convierten en una garantía para su movilidad personal y contribuyen de esa forma a que la persona discapacitada logre una mayor independencia y autonomía" (p. 14).

Señalar que para elegir un producto de las góndolas no se necesita la asistencia del perro guía muestra el poco grado de comprensión de estas situaciones, pues si me puedo valer de mi perro guía para sentarme en una mesa de un restaurante, ingresar a un recital, desplazarme en un supermercado, ir a los servicios, caminar a mi ritmo o ir a la salida del local en el momento que yo decida, ¿por qué me debería ver impedido de tener esa libertad, independencia y autonomía, que de por sí ya están limitadas por la discapacidad? De lo que se trata es de contribuir al goce máximo posible de este derecho.

Si la preocupación va por el lado de la higiene en el caso de los perros guía, bien hace el Tribunal en indicar que se llegaría hasta el extremo de 
restringir el acceso a todas las personas que tienen mascotas, debido a que podrían llevar el pelaje de sus perros u otras mascotas en sus prendas y contaminar los alimentos. Además, los perros guía no constituyen un peligro para el resto de las personas porque están adiestrados, de tal manera que se portan de manera respetuosa y no agresiva, sea con otros seres humanos o con algún animal con que interactúen.

De este modo, el Tribunal Constitucional, en el Expediente 024372013-PA (2014), luego de realizar el test de proporcionalidad para determinar si se encuentra justificada o no la medida adoptada por el supermercado que incide sobre el derecho de igualdad y no discriminación de las personas con discapacidad visual, concluyó que la medida resultaba excesiva y desproporcionada. Por tanto, declaró fundada la demanda de amparo y ordenó al supermercado que "permita que los demandantes con discapacidad visual ingresen en sus instalaciones acompañados de sus perros guía, garantizando su permanencia en tales locales de manera ilimitada, constante y sin trabas" (p. 21).

\section{¿Discriminación en los casos administrativos?}

Razones como las establecidas por el Tribunal Constitucional, me llevan a concluir que en los casos que se presentaron ante la autoridad administrativa de protección al consumidor se produjeron actos de discriminación. Considero que, aun cuando el consumidor haya podido acceder a un establecimiento abierto al público, es posible analizar la exclusión del lugar como un caso de discriminación.

Según se advierte en estos casos y en los que ocurrieron en el extranjero, se hubiera permitido al consumidor invidente hacer uso de los servicios ofrecidos, siempre y cuando dejara a su perro guía afuera del local, porque en la mente de quien trató con el consumidor, el perro guía podría incomodar a otras personas y transgredir las normas de sanidad. Sin embargo, lo que no tiene en cuenta es que el perro guía le da esa mayor independencia, libertad y autonomía para integrarse y desenvolverse.

Imaginemos que se presentan al establecimiento dos personas con discapacidad visual, una con y otra sin un perro guía. De acuerdo con la argumentación de los proveedores en los casos citados, quien podría ingresar, permanecer y hacer uso de los servicios del establecimiento es la persona sin el perro guía, pero el otro no. Entonces, ¿no estamos discriminando en ese caso? Y eso que nos encontramos ante dos personas que tienen la misma discapacidad. 
El tema se torna más grave aún, como realmente sucedió, porque se limita, se sabotea, se restringe el disfrute de los servicios ofrecidos por el proveedor a quienes hacen uso de sus perros guía frente a quienes sí podemos desenvolvernos con absoluta libertad, independencia y autonomía. ¿Se trata de una razón objetiva y justificada? De ninguna manera, pues no salimos de nuestra burbuja de un mundo pensado en personas sin discapacidad.

\section{ReFLeXiOnes finAleS}

Hemos dado un vistazo a casos desarrollados en la sede administrativa en el 2013 y 2017, así como uno resuelto en el Tribunal Constitucional en el 2014. También nos hemos referido a la experiencia comparada con tres casos en Costa Rica, resueltos en los años 2004, 2005 y 2011. Puedo apreciar que la lógica de los proveedores de bienes y servicios para el acceso y permanencia de personas con discapacidad visual asistidas por perros guía, lamentablemente, es similar. A pesar de los años transcurridos, continúa perjudicando el libre desenvolvimiento e integración de este grupo de personas.

Los casos administrativos pueden ser abordados como un problema de idoneidad, más que como un tema de atención preferente, pues el proveedor debería estar preparado para brindar el servicio sin restricciones a las personas con discapacidad visual; no se trata solo de poner una rampa o instalar servicios higiénicos para estos casos. Pero también considero que puede ser considerado como un caso de discriminación, pues el hecho de que haya podido ingresar al local no implica que no pueda ser rechazado a causa del perro guía, pues se le impone como condición que el can no entre para brindarle el servicio. Es como si le dijeran a una persona que no puede caminar y que quiere ingresar a un cine o a un restaurante que deje su silla de ruedas en la entrada, pues podría incomodar al resto de personas o ser un obstáculo para la entrada o salida del lugar.

En estos momentos, recuerdo el caso de una persona que tenía problemas para acceder con su silla de ruedas a una unidad de transporte, porque no estaba acondicionada para ello y tampoco tenía un número adecuado de unidades para brindar el servicio a esta consumidora. Nos convertimos en una de las principales trabas para que las personas con discapacidad visual puedan desarrollar sus actividades cotidianas, privándoles del uso de sus perros guía, que pueden darles 
mayor independencia, libertad y autonomía (reitero constantemente estas tres condiciones, pues deberíamos tenerlas muy presentes cuando estemos ante situaciones similares).

De acuerdo con el Instituto Nacional de Estadística e Informática (2018), solo nos estamos refiriendo, en este caso, a las personas invidentes, pues "existen otras limitaciones para moverse o caminar (462 mil 60 personas), para oír (232 mil 176 personas), para entender o aprender (127 mil 947 personas), para relacionarse con los demás (98 mil 836 personas), o para hablar o comunicarse (93 mil 88 personas)" (p. 186). La aplicación de las normas por parte de los operadores jurídicos, en general, va evolucionando, pero este tema muy relevante y sensible, que requiere que realmente nos pongamos en la posición de quien resulta afectado, aún tiene mucho camino por recorrer, tanto en las políticas de Estado como en la aplicación efectiva de las normas por parte de la ciudadanía, en su papel de proveedor y consumidor.

Dicen que nadie sabe lo que tiene hasta que lo pierde, eso es muy cierto en muchos casos, pero, en mi experiencia personal, siempre supe lo que tuve de parte de mi mascota, que no era perro guía, pero sí tenía su compañero invidente. Sí, no es falta de seriedad, pero permítame, estimado lector, unas brevísimas líneas finales para recordar a quien nos dio a su mamá humana y a mí muchas alegrías, sin pedir absolutamente nada a cambio. Se trata de un caso maravilloso de expresión de amor en su más alta pureza, sin necesitar palabra alguna para explicarse. Siempre supe el amor que me tenía, y si bien desde que se fue nada, pero nada, es igual, sigue presente con tal fuerza como el primer día que llegó a nuestras vidas. Como dice la cita inicial de este artículo: para quienes tienen este privilegio, un can se vuelve parte de ti, llegando a ser incluso, literalmente, tus ojos. Espero poder llegar a ser, por lo menos, la mitad de lo que Bombón me hacía sentir que yo era para ella. Estas líneas fueron escritas añorándola y agradeciéndole mucho.

\section{REFERENCIAS}

Carrión, A. (21 de julio del 2017). Conoce las muchas facetas de los canes en nuestras vidas [Especial: Día del Perro]. El Comercio. Recuperado de https://elcomercio.pe/wuf/conoce-muchas-facetas-perrovidas-443935 
Constitución Política del Perú. (1993). Recuperado del sitio de internet del Congreso de la República del Perú: http://www4.congreso. gob.pe/ntley/Imagenes/Constitu/Cons1993.pdf

Expediente02437-2013-PA/TC. (16 de abril del 2014). Tribunal Constitucional. Recuperado del sitio de internet del Tribunal Constitucional: https:// www.tc.gob.pe/jurisprudencia/2014/02437-2013-AA.pdf

Instituto Nacional de Estadística e Informática (INEI). (2018). Perú: Perfil sociodemográfico. Informe nacional. Censos Nacionales 2017: XII de Población, VII de Vivienda y III de Comunidades Indígenas. Recuperado de https://www.inei.gob.pe/media/MenuRecursivo/publicaciones_ digitales/Est/Lib1539/libro.pdf

Ley 29571, Código de Protección y Defensa del Consumidor. (2 de septiembre del 2010). Recuperado del sitio de internet de Indecopi: https://www.indecopi.gob.pe/documents/20195/177451/ CodigoDProteccionyDefensaDelConsumidor\%5B1\%5D. pdf/934ea9ef-fcc9-48b8-9679-3e8e2493354e

¿Por qué hay tan pocos perros guía en el Perú? (23 de mayo del 2016). Perú21. Recuperado de https://peru21.pe/lima/hay-perros-guiaperu- 218807

Resolución 2004-12802. (12 de noviembre del 2004). Sala Constitucional de la Corte Suprema de Justicia de Costa Rica.

Resolución 205-07768, Expediente 04-007842-007-CO. (17 de junio del 2005). Sala Constitucional de la Corte Suprema de Justicia de Costa Rica.

Resolución 2011-011418, Expediente 11-007603-0007-CO. (26 de agosto del 2011). Sala Constitucional de la Corte Suprema de Justicia de Costa Rica.

Resolución 331-2013/CC2, Expediente 184-2012/CC2. (18 de abril del 2013). Comisión de Protección al Consumidor 2.

Resolución 978-2017/CC2. (16 de junio del 2017). Comisión de Protección al Consumidor 2. Recuperado del sitio de internet de Indecopi: http://servicio.indecopi.gob.pe/buscadorResoluciones/ proteccion-consumidor.seam 